\title{
Rock typing based on hydraulic and electric flow units for reservoir characterization of Nubia Sandstone, southwest Sinai, Egypt
}

\author{
Abdel Moktader A. El-Sayed ${ }^{1} \cdot$ Nahla A. El Sayed ${ }^{2} \cdot$ Hadeer A. Ali $^{1} \cdot$ Mohamed A. Kassab ${ }^{2} \cdot$ Salah M. Abdel-Wahab $^{1}$. \\ Moataz M. Gomaa ${ }^{1}$
}

Received: 9 September 2020 / Accepted: 19 July 2021 / Published online: 3 August 2021

(c) The Author(s) 2021

\begin{abstract}
The present work describes and evaluates the reservoir quality of the sandstone of the Nubia Formation at the Gebel Abu Hasswa outcrop in southwest Sinai, Egypt. Hydraulic flow unit (HFU) and electrical flow unit (EFU) concepts are implied to achieve this purpose. The Paleozoic section made up of four formations has been studied. The oldest is Araba Formation followed by Naqus formations (Nubia C and D) overlay by Abu Durba, Ahemir and Qiseib formations (Nubia B), where the Lower Cretaceous (Nubia A) is represented by the Malha Formation. The studied samples have been collected from Araba, Abu Durba, Ahemir and the Malha formations. The hydraulic flow unit (HFU) discrimination was carried out based on permeability and porosity relationship, whereas the electrical flow unit (EFU) differentiation was carried out based on the relationship between formation resistivity factor and porosity. Petrographic investigation of the studied thin sections illustrates that the studied samples are mainly quartz arenite. Important roles to enhance or reduce the pore size and/or pore throats controlling the reservoir petrophysical behavior are due to the diagenetic processes. The present study used the reservoir quality index (RQI) and Winland $\mathrm{R}_{35}$ as additional parameters applied to discriminate the HFUs. The study samples have five hydraulic flow units of different rock types, where the detected electrical flow units are only three. The differences between them are may be due to the cementation process with iron oxides that might act as pore filling, lining and pore bridging, sometimes bridges helping to decrease permeability without serious reduction in porosity. The reduction between the number of EFUs and HFUs comes from the effect of diagenesis processes which is responsible for a precipitation of different cement types such as different clay minerals and iron oxides.
\end{abstract}

Keywords Hydraulic flow unit · Electric flow unit · Paleozoic age · Nubia sandstone · Gebel Abu Hasswa

\section{Introduction}

Hydraulic flow units are defined for the first time by Amaefule et al. (1993a, b), and then, this concept has been tested and applied for many years by many researchers, e.g., El Sharawy and Nabawy (2016a, b), Kassab and Teama (2018), Nabawy and Barakat (2017), Teama et al. (2019), Tiab and Donaldson (2016). They defined the HFU as the part of the rock volume that has one or more rock quality lithology. One of the important characteristics of the flow unit can be

Mohamed A. Kassab

mkassab68@yahoo.com

1 Geophysics Department, Faculty of Sciences, Ain Shams University, Cairo, Egypt

2 Exploration Department, Egyptian Petroleum Research Institute, Cairo, Egypt mapped at the interval scale. Nevertheless, the discrimination between the different quality of the flow units can be derived based on hydraulic or electric characteristics. Rezaee et al. (2007) used the relation between electric properties with petrophysical parameters to detect the different EFU.

Nubia sandstone has been studied by El Sharawy and Nabawy (2019), Kassab et al. (2017) and David et al. (2015). The reservoir characterization of the Nubia sandstone reservoir demonstrates that it has excellent potential for hydrocarbon production (Sarhan and Basal 2019), so that the Nubia sandstone is considered as an important reservoir rocks in Egypt and the surroundings.

The subsurface occurrence of Nubia Formation has been studied by Alsharhan and Salah (1997) and indicated that the potential reservoirs are formed in the Araba, Naqus, Qiseib and Malha formations within the Nubian facies, while the Umm Bogma Formation acts as seal, and Abu Durba

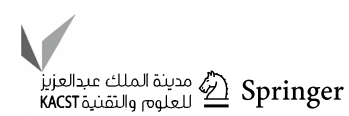


Formation has been studied by Nabawy and Géraud (2016), who stated that the Abu Durba Formation has a well flow capacity properties, and the Rod El Hamal Formation acts as a source unit. Khalil (1987) divided the Nubia sandstone into three parts. The lower part (Nubia C) varies in the lithology from fine to coarse, conglomeratic, friable and partly kaolinitic, white to brownish sandstones.

The Nubian sandstones in Egypt and the surroundings have been studied by several authors. The first deposits of the pre-rift sediments in the Neogene Suez Rift are formed mainly from Nubian sandstones (Garfunkel and Bartov 1977). This sandy formation in the western coast of the Sinai Peninsula is up to $600 \mathrm{~m}$ thick (Robson 1971) and mostly includes continental deposits (Schutz 1994). The sediments in the study area (Gebel Abu Hasswa) are mostly fluvial )Said 1962). The pre-rift marine formations that conformably cover the Nubian sandstones are resulted from a major Cenomanian transgression (Schutz 1994). Himida (1970), Issar et al. (1972) and Shata (1982) stated that Nubian sandstone is underlying an extensive area of Egypt and probably constitutes a single hydrogeological system to the West of the Gulf of Suez. To the East, on the Sinai Peninsula, a second system may exist with some connection to the main western system in the North.

The middle part (Nubia B) is represented by gray to green, marine shales, silty with thin interbeds of sandstones, fine to medium grained, silty (El-Gendy et al. 2017) and clayey with abundant trace fossils, probably Permo-Carboniferous in age. The upper part (Nubia $\mathrm{A}$ ) is represented by fluviatile sandstone, fine to medium, coarse to conglomeritic, massive through cross-bedded showing direction of transportation from south to north, interbedded mudstones, varicolored, well stratified with root structures.

The Paleozoic Nubia is classified into four rock units: Araba, Naqus, Abu Durba and Ahemir formations (ElBarkooky 1986; Wanas 2011) on both sides of the Nile Valley. The depth to the Nubian aquifer in Egypt can significantly vary from appearing on the ground up to $3500 \mathrm{~m}$ below the ground surface with an average thickness of thousands and decreases toward the north (Abdel Moneim et al. 2015); meanwhile, El-Rawy and Smedt (2020) stated that the thickness of the aquifer ranges from 300 to $3500 \mathrm{~m}$ with a very complex geometry. The isotopic data interpreted in conjunction with conventional hydrologic data have confirmed the fact that North Western Sahara aquifer system is receiving a considerable fraction of modern water recharging the aquifer (Al-Gamal 2011).

In the East Central Sinai, Nubia sandstone is studied petrophysically by Hassan et al. (1994), El Sayed (1995) and El Sayed et al. (2008). Only two genetic sand body types have been recognized in Wadi Saal (NE Saint Catherine). The recognized lower sand unit was distributary mouthbar followed by the upper one described as barrier island sandstone or sand bars. The mode of occurrence, volume of kaolinite effective porosity, recovery efficiency, irreducible water saturation and displacement pressure of the Nubia Sandstone in Wadi Saal were discussed by El Sayed (1995). He concluded that the formation fines have a great effect on the Nubian sandstone reservoir quality. El Sharawy and Gamal (2019) studied the capillary pressure and petrophysical properties of the Nubia facies. Fifty one surface samples were collected from the outcrops at Gebel Abu Hasswa to represent the different lithofacies of the Nubia Sandstone units in the eastern side of Gulf of Suez. The study area is located between Latitude $28^{\circ} 20^{\prime}-28^{\circ} 40^{\prime} \mathrm{N}$ and Longitude $33^{\circ} 10^{\prime}-33^{\circ} 30^{\prime} \mathrm{E}$ as shown in Fig. 1.

The main objective of this study is to delineate the importance of the Nubia sandstone rocks of Abu Hasswa section as a Paleozoic reservoir in the mean offshore areas, by testing different petrophysical parameters and to divide this reservoir into both hydraulic flow units and electric flow units.

\section{Geological setting}

Abu Hasswa outcrop section covers an area of about 15 square $\mathrm{km}$. The Gulf of Suez depression is characterized by several ridges and basins trending NW-SE dissected by the parallel fault blocks and shear zones. West Sinai area is strongly affected by the tension tectonic movements and often belongs to the Gulf of Suez tectonic province where

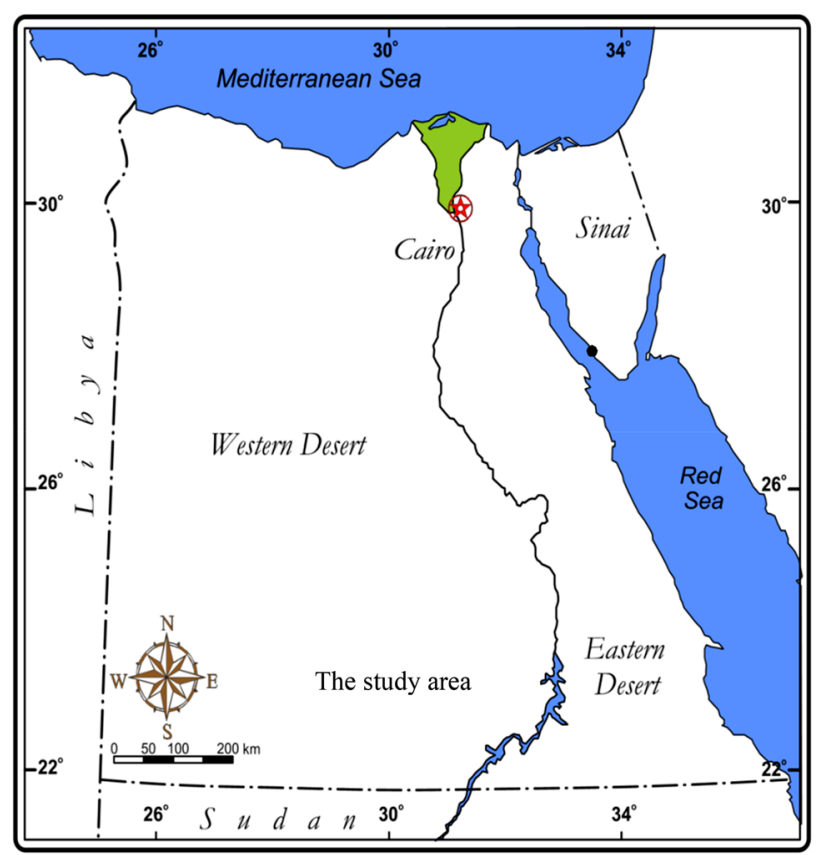

Fig. 1 The location of the study area (Gebel Abu Hasswa) 


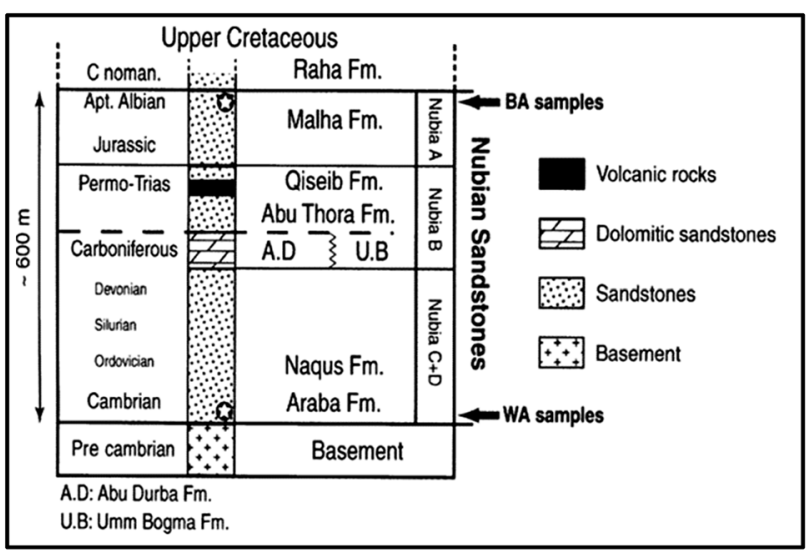

Fig. 2 Stratigraphic column of the Nubian sandstones in the western coast of the Sinai Peninsula, Egypt (modified after Schutz 1994)

faults play the main role in tectonic deformation (Sarhan and Basal 2019).
Figures 2 and 3 show lithostratigraphic section of Nubia sandstone at Gebel Abu Hasswa, while the collected sample numbers from each formation are presented. The Nubia formations from bottom to the top are: Araba Formation was first described by Hassan (1967). It overlies unconformably the basement rocks (Precambrian rock) and underlies the Naqus Formation. It attains $61 \mathrm{~m}$. It consists of yellowish brown, varicolored, cross-bedded sandstone (the grains are fine to medium in size), with fine streaks of shale. Abu Durba Formation is recognized by Abdallah and Adindani (1965). It rests unconformably on Naqus Formation and underlies Ahemir Formation, and it attains $60 \mathrm{~m}$ thickness. This formation is characterized by a dark brown to red sandstone and claystone with some evaporitic patch and dolomitic streaks. Aheimer Formation is recognized by Abdallah and Adindani (1965). It overlies on Abu Durba Formation and underlies Qiseib Formation. It reaches $45 \mathrm{~m}$ in thickness. It is composed of dark purple to varicolored claystone alternating with siliceous and calcareous sandstones

\begin{tabular}{|c|c|c|c|c|}
\hline Age & Fm. & S.no. & Lith. & Description \\
\hline L. Cret. & Malha & 6 & 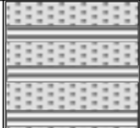 & $\begin{array}{l}\text { Sandstone; yellowish brown, pink to purple colour } \\
\text { occasionally alternated with claystone. }\end{array}$ \\
\hline \multirow[t]{2}{*}{$\begin{array}{l}\text { Permo } \\
\text { Triassic }\end{array}$} & Qisieb & 0 & 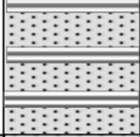 & $\begin{array}{l}\text { Sandstone; yellowish red to white, hard, alternated } \\
\text { with gypsiferous kaolinite clay. }\end{array}$ \\
\hline & Aheimer & 10 & (n) & $\begin{array}{l}\text { Claystone; dark purple to variocoloured alternated } \\
\text { with siliceous sandstone and calcareous sandstone layers. }\end{array}$ \\
\hline $\begin{array}{l}\text { Carbonif- } \\
\text { erous }\end{array}$ & $\begin{array}{l}\text { Abu } \\
\text { Durba }\end{array}$ & 3 & किसे & $\begin{array}{l}\text { Sandstone and claystone; dark brown to red with } \\
\text { some evaporitic patch and dolomitic streaks. }\end{array}$ \\
\hline $\begin{array}{l}\text { Up ord. } \\
\text { to } \\
\text { L.Silurian }\end{array}$ & Naqus & 0 & & $\begin{array}{l}\text { Sandstone; white colour, rare organic matter, coarse } \\
\text { pebbles and gravels are intercalated with } \\
\text { sands in repeated manner. } \\
\text { Kaolinite cementation are common so, } \\
\text { it is friable, it is highly cross bedded. }\end{array}$ \\
\hline $\begin{array}{l}\text { Cambro } \\
\text { Ordovician }\end{array}$ & Araba & 32 & & $\begin{array}{l}\text { Sandstone; yellowishh brown, varicoloured, fine to } \\
\text { medium grained cross bedded with fine streaks of shale } \\
\text { and organic matter with vertical tubes of } \\
\text { skoliths and cruziana. }\end{array}$ \\
\hline \multirow[t]{2}{*}{$\begin{array}{l}\text { Pre- } \\
\text { Camb. }\end{array}$} & \multicolumn{2}{|c|}{ Basement } & & Basement rocks. \\
\hline & Basement & & $\begin{array}{l}\because \because \cdots \\
\text { Sandst. }\end{array}$ & $\stackrel{5 \quad 0}{\text { Conglomerate }}$ \\
\hline
\end{tabular}

Fig. 3 Detailed lithologic column and Nubia sandstone samples locations at Gebel Abu Hasswa, western coast of the Sinai Peninsula, Egypt 
with dolomitic limestone bands. Malha Formation overlies unconformable Qiseib Formation and consists of varicolored (yellowish brown, pink and purple) sandstone, alternated with claystone occasionally. It reaches a thickness of $100 \mathrm{~m}$. It has been dated as lower Cretaceous.

\section{Theoretical background}

Flow unit concept is defined to shape the description of reservoir zones as a function of storage capacity and fluid flow capacity, which are resulted from diagenetic processes and depositional conditions. Most common use for this concept is to predict the permeability of each rock quality as can be shown in Hassan et al. (2014), Shabaninejad and Bagheripour Haghighi (2011) and Al-Ajmi and Holditch (2000).

\section{Hydraulic flow unit (HFU) concept}

A flow unit is defined by Amaefule et al. (1993a, b) as a reservoir zone with lateral continuity between wells and internally consistent characteristics that control fluid flow and are distinct from those of adjacent flow units. Hydraulic quality of rocks is controlled by pore geometry, radius, tortuosity, specific surface, mineralogy and its morphology side by side with textural parameters as sorting, packing, grain size and shape. It is the selection of samples of the same pore attributes that can be clustered in the similar hydraulic unit. The boundaries of rock genetic units described by a geologist may be useful for the reservoir engineer if they coincide with distinctive changes in flow properties. It is based on the Kozeny-Carman equation and its modifications:

$\boldsymbol{k}=\frac{\varnothing^{3}}{(1-\varnothing)^{2}} *\left(\frac{1}{\boldsymbol{k}^{\circ} * \boldsymbol{\tau} * \boldsymbol{S g} v^{2}}\right)$

where $\mathrm{K}=$ permeability, md; $\varnothing=$ fractional porosity; $\tau$ is the electrical tortuosity and can be measured from electrical resistivity measurement; $\mathrm{k}^{\mathrm{o}}$ is a shape factor; and $\mathrm{S}_{\mathrm{gv}}$ is the specific surface area per unit grain volume.

The objective is to avoid measuring these microscopic properties by gathering these parameters into a single variable called the flow zone indicator (FZI). The previous equation can be adjusted to be;

$\sqrt{\frac{\boldsymbol{k}}{\varnothing}}=\left(\frac{\varnothing}{1-\varnothing}\right) *\left(\frac{1}{\sqrt{\boldsymbol{K}^{\circ} \boldsymbol{\tau}} * \boldsymbol{S g} \boldsymbol{v}}\right)$

The porosity and permeability ratio can be defined as reservoir quality index (RQI);

$$
R Q I=0.0314 \sqrt{\frac{K}{\varnothing}}
$$

Flow zone indicator (FZI) indicates samples with similar pore throat characteristic, where the larger grain size will have the greater FZI and the greatest permeability. It can be defined as a function of tortuosity and the specific surface area per unit grain volume:

$$
\boldsymbol{F Z I}=\frac{1}{\sqrt{K z} * S g v}
$$

The pore-to-grain volume ratio $\left(\varnothing_{\mathrm{z}}\right)$ can be defined as normalized porosity;

$\varnothing z=\frac{\varnothing}{1-\varnothing}$

According to Kozeny-Carman equation and hydraulic radius, Amaefule et al. (1993a, b) developed a relation for grouping the data fitting to their flow zone that can be expressed as:

$\log (R Q I)=\log (\varnothing z)+\log (F Z I)$

RQI with $\varnothing z$ relationship on a $\log -\log$ scale showed that the core samples with the same pore geometry will lie on a straight line with a diagnostic slope, while dissimilar samples will lie on different parallel lines. To simplify the use of FZI in expressing reservoir type (Shenawi et al. 2007), FZI can be transformed to discrete rock type (DRT) by;

DRT $=\operatorname{Round}(2 * \ln (\mathbf{F Z I})+10.6)$

Subsequently, a log-log plot of RQI versus $\emptyset_{\mathrm{z}}$ will result in a unit slope with a y-intercept equal to FZI at $\emptyset_{z}=1.0$. Each straight line has samples of similar pore characteristics and is therefore considered a flow unit. Samples with different FZI values will lie on different but parallel lines.

Inland method is used capillary pressure technique to estimate the pore throats size distribution for rock typing examination and constructing iso-pore throats radius lines. Use these Winland iso-pore throat radius lines to divide the porosity-permeability into several rock units depending on the pore throats radius. Winland equation was published by Kolodzie (1980) as shown below:

$\left.\log \left(R_{35}\right)=0.732+0.588 \log K\right)-0.864 \log (\varnothing)$

where $\mathrm{R}_{35}=$ pore throat radius corresponding to the 35 th percentile mercury saturation, microns, $\varnothing=$ porosity ambient conditions, $\%$, and $\mathrm{K}=$ air permeability ambient conditions, $\mathrm{md}$. There are the five petrophysical flow units with distinctive reservoir performance differentiated by $R_{35}$ method (Winland 1972), as follows: (1) megaporous units, when $R_{35}$ is more than 10 microns, (2) macroporous units, when $R_{35}$ is more than 2.5 and less than 10 microns, (3) mesoporous units, when $\mathrm{R}_{35}$ is more than 0.5 and less than 2.5 microns, 
(4) microporous units $\left(0.2<\mathrm{R}_{35}<0.5\right.$ microns) and (5) nanoporous units ( $\mathrm{R}_{35}<0.2$ microns).

\section{Electrical flow unit (EFU)}

The formation resistivity factor $(\mathrm{F})$ was studied by many authors, such as El Sayed and Zeidan (1983) where the formation resistivity factor is a function of the electric pore throat radius and the effective cross-sectional area available for electric conduction. Rezaee et al. (2007) introduced a new technique for classifying porosity and formation resistivity factor, like hydraulic flow unit concept as:

$E R I=\sqrt{\frac{\varnothing}{F}}$

where ERI is the electrical radius indicator, $\varnothing$ is the porosity (\%), and $\mathrm{F}$ is the formation resistivity factor. Rezaee et al. (2007) established a new approach to classify F data based on current zone indicator (CZI) and electrical flow unit (EFU) that showed the comparison between RQI and ERI and indicated that ERI can be matched with RQI, many authors (e.g. Zhang and Knackstedt 1995; Hilfer and Manwart 2001; Slater and Lesmes 2002) discussed the lack of match between RQI and ERI by showing that the electrical and hydraulic pathways are not identical.

ERI is controlled by the electrical radius for each sample. In order to separate samples with similar electrical flow properties, ERI must be divided into volume of void space or pore-to-matrix volume ratio (normalized porosity) $\varnothing_{\mathrm{z}=}$ $(\varnothing / 1-\varnothing)$;

$C Z I=\frac{E R I}{\varnothing z}$

where CZI is the current zone indicator, and the study samples can be distinguished to multiple electric flow units according to their CZI.

\section{Materials and methods}

In the present work, the studied samples have been collected from Araba, Abu Durba, Ahemir and the Malha formations. (Fifty-one rock samples were collected from Nubia Sandstone, where thirty-two samples are obtained from the Araba Formation, three samples are from the Abu Durba Formation, ten samples are from the Ahemir Formation, and the rest are from the Malha Formation). These samples have been conducted to several laboratory measurements. The available specimens of Abu Hasswa section were cut into cylinders using a laboratory diamond drill. All samples plugs were of $2.5 \mathrm{~cm}$ in diameter and ranged from 3.5 to $4.0 \mathrm{~cm}$ in length (API Specifications 1960).
The samples need to remove any moisture content or residual fluids before the petrophysical measurements. The Soxhlet extraction apparatus method was used for cleaning the Nubia sandstone samples, and methanol was used for salt-laden water removal, without causing any alteration for the sample original pore space geometry. More than one solvent was used for complete cleaning until the siphoned liquid was colorless.

The study samples were dried in a vacuum controlled temperature oven at a temperature of 60 centigrade for $48 \mathrm{~h}$ (API Specifications 1960). The weight before and after drying was calculated using an electrical balance in order to measure the moisture content that was about $0.1 \mathrm{mg}$.

To avoid any lithologic rugosity, the rock ships were taken out from one end and the same prepared cylindrical sample. Eleven thin sections of the Nubia sandstone were prepared from core samples representing the Nubia sandstone of Abu Hasswa section using blue dye pigment to provide a better estimation of different pore spaces types (Williams and Patel 2016). Careful investigation and description of thin sections were carried out using a polarizing microscope.

A total of 51 sandstone core samples were tested for porosity and permeability. All samples were dried at low temperature for several days in an oven. Porosity was measured by using of helium porosimeter, and it is defined as the volume of pore space divided by the bulk volume of the sample.

Ruska Gas Permeameter (Hassler-type core holder) was used for permeability measurements for the study samples where each sample was inserted individually into the core holder and surrounded by sealing-stopper, while nitrogen gas was injected through the samples at constant pressure $(0.5 \mathrm{Atm})$. The flow rate of the gas and the pressure difference across the length of each sample were measured.

The electrical resistivity (Ro) was measured when samples were fully saturated by brine with water resistivity $(\mathrm{Rw}=0.071 \Omega \cdot \mathrm{m}$., for salinity $60,000 \mathrm{ppm})$ using of Core Lab Inc A.C. Bridge (Model 100A). Electrical resistance (r) of the samples was measured along the axis of cylindrical plug. Then, resistivity $(\mathrm{R})$ was calculated from the measured resistance (r) using the cross-sectional area of the core (A) and the length of the core (L). Formation factor was obtained as a ratio of rock resistivity (Ro) to brine resistivity (Rw) as:

$F=R o / R w$ 


\section{Results and discussion}

\section{Petrographic investigation}

Petrographic investigation of the studied thin sections illustrates that the studied samples are mainly quartz arenite depending on rock framework and digenetic processes. It is composed of quartz grains cemented by silica. Quartz grains are coarse to medium sand size, subrounded to subangular, moderately sorted. Silica cement is represented by intergranular microcrystalline silica in addition to silica overgrowth. Diagenetic processes are dominated by cementation and compaction. The former is evidenced by silica. The latter process is evidenced by grain contact which represented by straight and rare suture contact and convex-concave contact, and they are the main porosity-reducing factors (Fig. 4a), while the dissolution process caused oversized porosity and
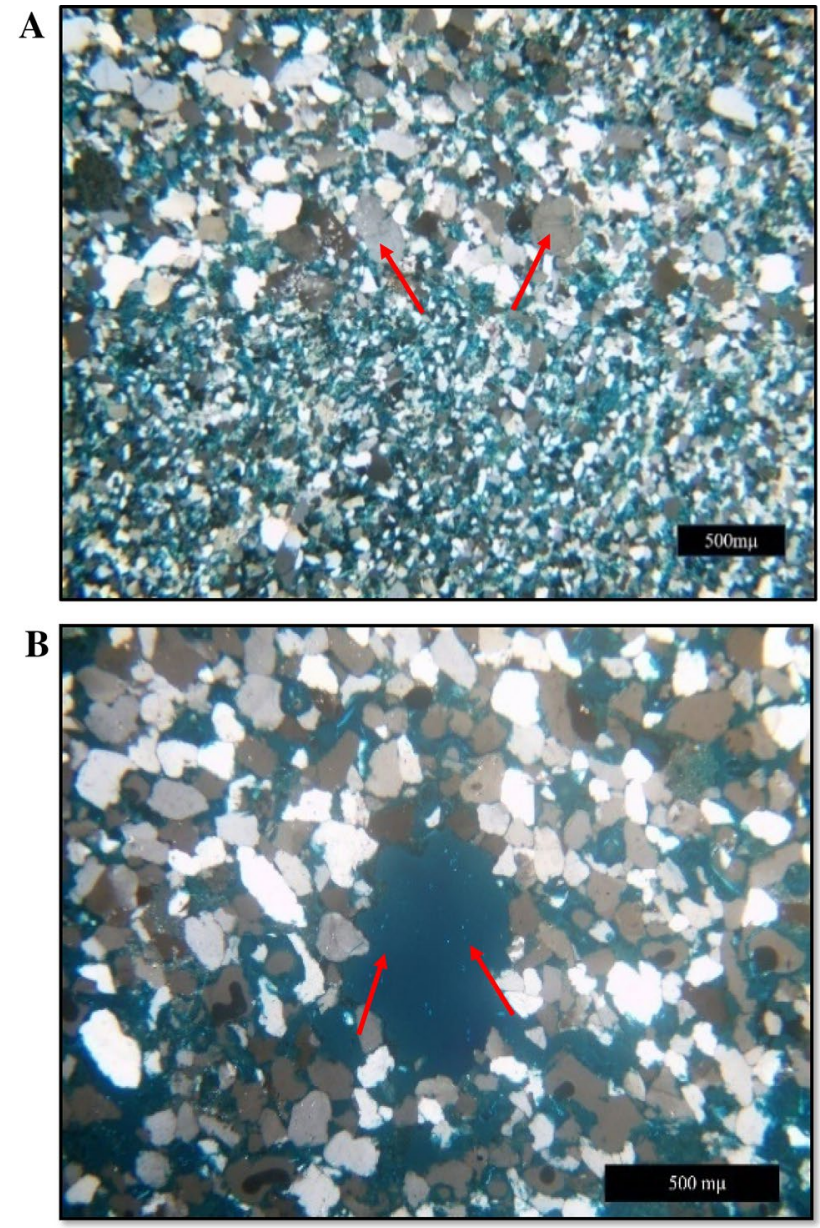

Fig. 4 a The photomicrographs (A) and (B) show quartz arenite microfacies; the photomicrographs (A) show quartz grains cemented by silica and iron (stained by blue dye pigment), XP. The photomicrograph $\mathbf{b}$ shows dissolution process caused oversized porosity, XP led to increase in porosity (Fig. 4b). The origin of this rock is igneous rock; it has medium porosity with medium permeability. The Abu Hasswa rock samples are slightly heterogeneous, and diagenetic processes could affect the pore throat radius.

\section{Permeability-Porosity relationship}

The range of values of the porosity, the permeability, the predicted permeability and the flow zone indicator values for all samples collected from all formations (Fms) from Abu Hasswa section are shown in Table 2, while the range of values of the porosity, the permeability, the predicted permeability and the flow zone indicator values for the samples collected from each formation (Fm) (Araba, Abu Durba, Ahemir and the Malha formations) at Abu Hasswa section are shown in Table 3. Ahemir Formation has the highest value of porosity, the highest value of permeability, the highest value of predicted permeability and the highest value for formation zone indicator.

The relationship between permeability and porosity is characterized by a fair coefficient of correlation $\left(R^{2}=0.4567\right)$. The measured permeability of the studied samples is affected mainly by the pore throat radius and digenetic factors. The low correlation between porosity and permeability is usually happened because we treat all the studied sandstone formations as one single population (El Sayed and El Sayed 2019).

Figure 5 shows the relationship between permeability and porosity of all samples obtained from the Abu Hasswa section. It exhibits a very weak positive trend which needs mathematical processing to pick similar reservoir lithotypes in one single sample population. The hydraulic flow unit

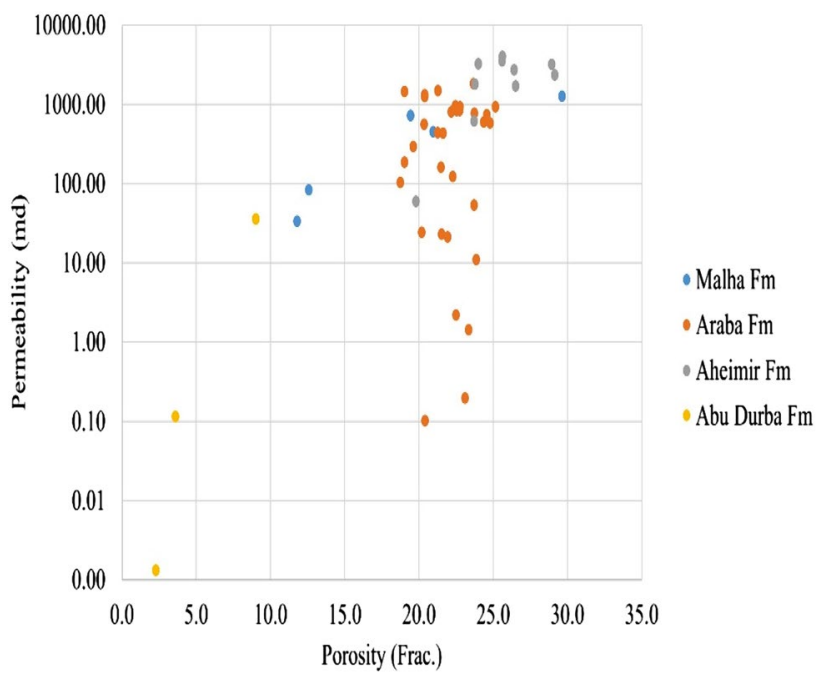

Fig. 5 The relation between permeability and porosity of Abu Hasswa samples 
(HFU) concept is applied for the studied samples to discriminate the different hydraulic flow units, evaluate rock quality and quantify the heterogeneity of the reservoir. The number of HFUs is controlled by the random errors in the measurement of both porosity and permeability data. The magnitude of the random errors can be estimated by calculating the root mean square of the difference between the actual and predicted values of permeability for each HFU discrimination.

Figure 6 shows the estimation of root-mean-square (RMS) error of permeability prediction values of $1,2,3$, 4, 5 and 6 HFUs, where the difference between the RMS error of HFU 5 and 6 is very small which indicates the exact number of HFU for the studied Nubia sandstone samples.

\section{Hydraulic flow units}

Figure 7 shows porosity and permeability relationship superimposed with Winland $R_{35}$. This figure classified the hydraulic flow units (HFUs) based on both $\mathrm{R}_{35}$ and FZI values. The obtained five hydraulic flow units (HFU1, HFU2, HFU3, HFU4 and HFU5) have been distinguished by comparable average values of $R_{35}$ and the FZI values. Megaporous unit represents the HFU5, with high porosity and permeability values and with average value of $R_{35}=31.8$. Macroporous unit represents the HFU4, with average value of $R_{35}=15.3$. The HFU3 is represented by mesoporous flow units, and with average value of $R_{35}=3.2$. The HFU2 is represented by mesoporous to microporous flow units, and finally, the HFU1 represents the very tight pore spaces of impervious unit with average value of $R_{35}=0.121$ and has a very low values of porosity and permeability due to cementation in some parts (Fig. 7). The relation between $\mathrm{R}_{35}$ and FZI (Fig. 8) shows an excellent correlation $\left(\mathrm{R}^{2}=0.92\right)$, and the calculated regression equation controlling this relation is:

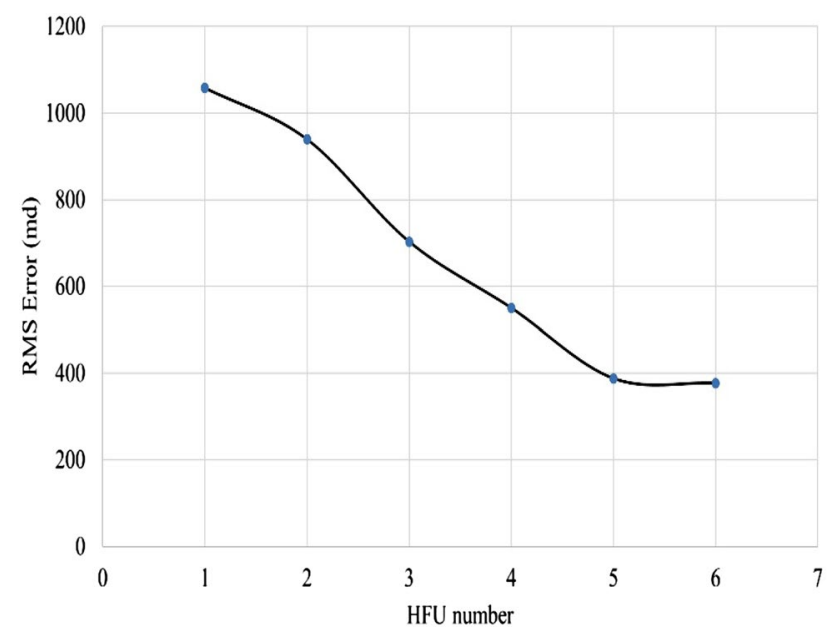

Fig. 6 RMS error calculation of HFU clusters

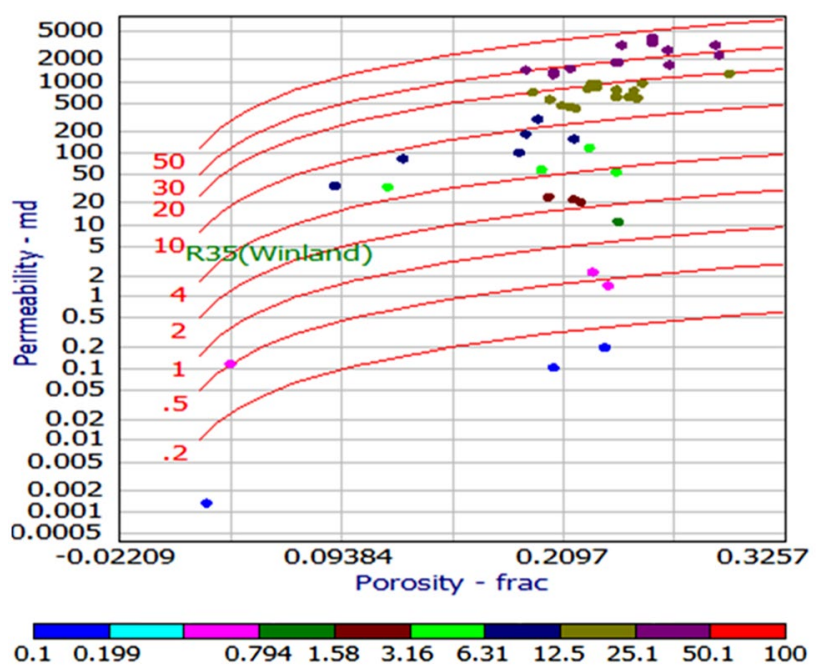

Fig. 7 Porosity-Permeability relationship of Nubia sandstone samples with $\mathrm{R}_{35}$ (Winland) lines

$R_{35}=0.20781+1.28182 * \log (\mathrm{FZI})$

The studied Nubia sandstone samples are statistically treated as one population. The calculated values of FZI at $\emptyset_{\mathrm{z}}=1.0$ for the samples of the Abu Hasswa section are varied from 0.09 to 11.71 with mean value of 5.37 and standard deviation of 3.32 variance value of 11.01 , and median value of 5.53, while the mean values of samples obtained from the Malha, Araba, Abu Durba and Ahemir formations are 5.6, $4.74,2.72$ and 8.09, and standard deviation of 1.48, 3.24, 3.18 and 2.93 , respectively.

Figure 9 shows the cross-plot of RQI versus $\emptyset_{z}$. Figure 10 shows that the relationship between permeability and

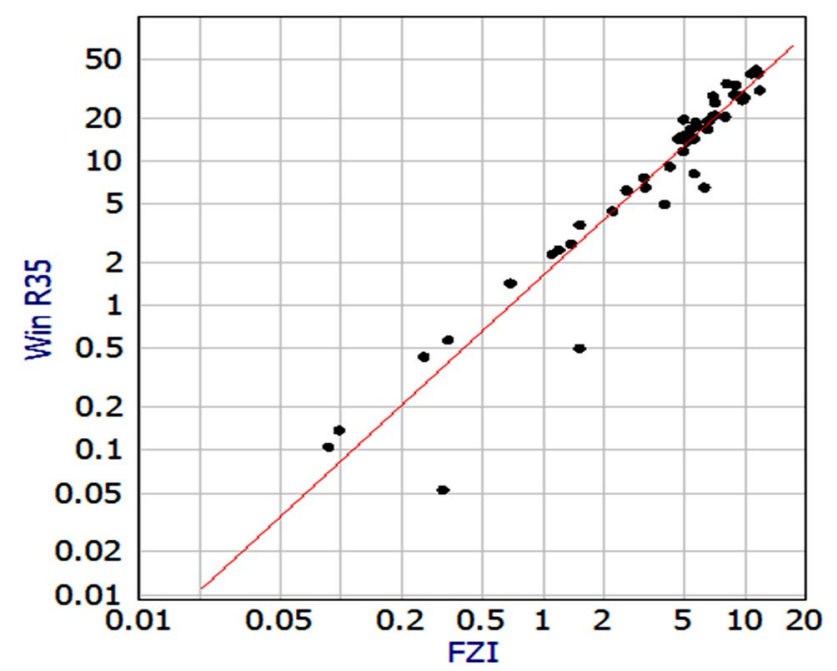

Fig. 8 The relation between Win $\mathrm{R}_{35}$ and FZI 


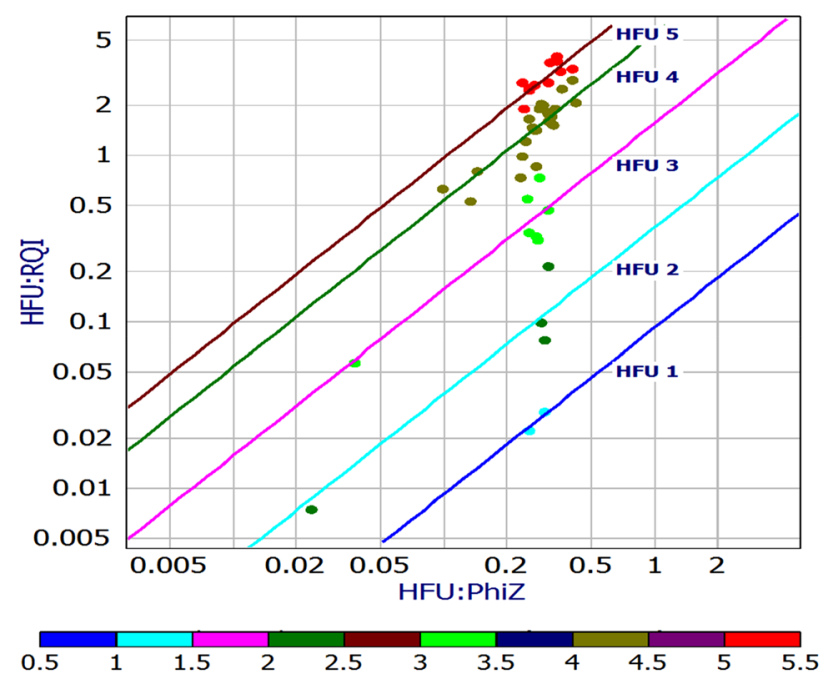

Fig. 9 The relation between RQI and pore to grain volume

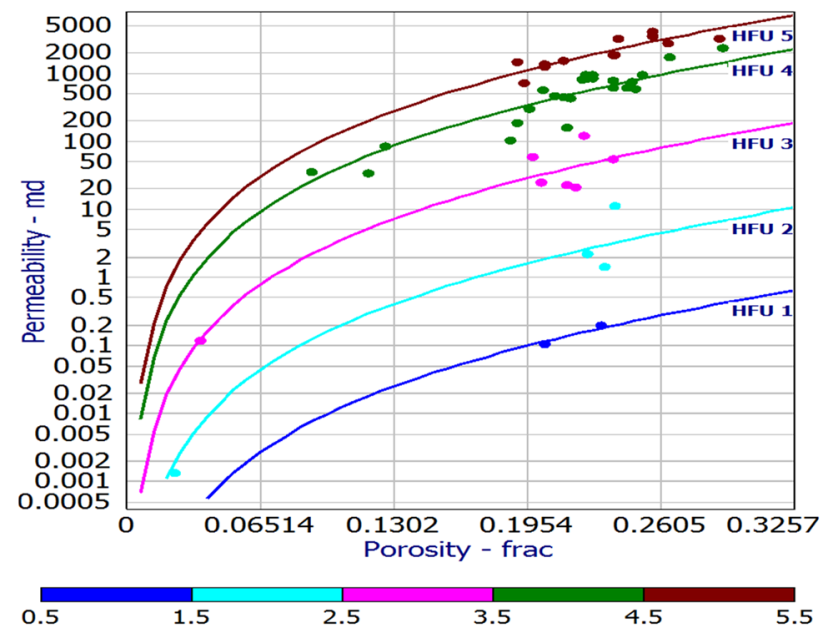

Fig. 10 Porosity-Permeability relationship of all the study samples with HFU

porosity can be divided into five lithotype groups (HFUs) from one to five, where HFU1 is the higher reservoir quality unit and HFU5 is the lowest reservoir quality unit. The correlation coefficients of the determined HFUs are tabulated
(Table 1). The derived equations were used for permeability prediction (Tables 2 and 3) for all the study samples. Figure 11 shows the relation between the predicted permeability on the $\mathrm{x}$-axis and the actual permeability on the $\mathrm{y}$-axis with very high correlation coefficient $R^{2}=0.9803$.

\section{Electric flow units}

Table 4 shows the range of the formation resistivity factor, the tortuosity, electrical resistivity indicator values for all the samples collected from all formations from Abu Hasswa section with concentrations of $6000 \mathrm{ppm} ., 30,000 \mathrm{ppm}$. and $60,000 \mathrm{ppm}$., while Table 5 shows the range of the formation resistivity factor, the tortuosity, electrical resistivity indicator values for the samples collected from each formation (Fm) (Araba, Abu Durba, Ahemir and the Malha formations) at Abu Hasswa section with concentrations of 6000 ppm., 30,000 ppm. and 60,000 ppm., and Abu Durba Formation has the highest value for formation resistivity factor values at concentration of $6000 \mathrm{ppm}$., at concentration of 30,000 ppm. and at concentration of 60,000 ppm. Abu Durba Formation has the highest value for tortuosity values for brine concentration of $60,000 \mathrm{ppm}$.

Araba Formation has the highest electrical resistivity indicator value for brine concentration of $60,000 \mathrm{ppm}$. and has the highest value for values of current zone indicator for brine concentration of $60,000 \mathrm{ppm}$.

The relationship between porosity and the formation resistivity factor $(\mathrm{F} 1, \mathrm{~F} 2$ and $\mathrm{F} 3)$ at $\mathrm{Rw}=0.619,0.16$ and 0.08 at brine concentration is $6000,30,000$ and $60,000 \mathrm{ppm}$., of $\mathrm{NaCl}$, respectively, as shown in Tables 4 and 5 and in Fig. 12, with correlation coefficients of $0.626,0.767$ and 0.794 , respectively. The multiplier (a) and cementation factor $(\mathrm{m})$ of the general form of Archie's second equation can be calculated from the intercept and slope for regression lines, where $(\mathrm{a})=2.86,3.232$ and 3.04 and $\mathrm{m}=-1.322$, -1.333 and -1.318 , respectively. The obtained three lines are almost coinciding on each other's. The electrical resistivity indicator (ERI) is a function of an electrical current propagation radius for each rock sample (Rezaee et al. 2007).

$=-3.5581$. To separate samples with similar electrical flow properties, (ERI), it must be divided on the ratio
Table 1 HFUs estimated equations with $\mathrm{R}^{2}$, FZI and DRT

\begin{tabular}{lllll}
\hline HFU & Equations & $\mathrm{R}^{2}$ & FZI, $\mu \mathrm{m}$ & DRT, $\mu \mathrm{m}$ \\
\hline 1 & $\mathrm{~K}=\varnothing^{\wedge} 3 *(0.092 /(0.0314 *(1.0-\varnothing)))^{\wedge} 2$ & 0.90 & 0.092 & 6 \\
2 & $\mathrm{~K}=\varnothing^{\wedge} 3 *(0.371 /(0.0314 *(1.0-\varnothing)))^{\wedge} 2$ & 0.95 & 0.4 & 9 \\
3 & $\mathrm{~K}=\varnothing^{\wedge} 3 *(1.566 /(0.0314 *(1.0-\varnothing)))^{\wedge} 2$ & 0.93 & 1.6 & 12 \\
4 & $\mathrm{~K}=\varnothing^{\wedge} 3 *(5.395 /(0.0314 *(1.0-\varnothing)))^{\wedge} 2$ & 0.83 & 5.4 & 14 \\
5 & $\mathrm{~K}=\varnothing^{\wedge} 3 *(9.71 /(0.0314 *(1.0-\varnothing)))^{\wedge} 2$ & 0.74 & 9.71 & 15 \\
\hline
\end{tabular}

where $\mathrm{K}$ is permeability; $\emptyset$ is porosity; FZI is flow zone indicator; HFU is hydraulic flow units; and DRT is discrete rock type 
Table 2 Porosity, measured and predicted permeability and calculated flow zone indicator of Abu Hasswa samples

\begin{tabular}{llcrr}
\hline Petrophysical parameters & Min & \multicolumn{1}{c}{ Max } & \multicolumn{1}{c}{ Mean } & \multicolumn{1}{c}{ Std. Dev } \\
\hline$\varnothing \%$ & 2.3 & 29.6 & 21.344 & 5.359 \\
K, md & 0.001 & 4027.65 & 877.665 & 1030.021 \\
K, md (Predicted) & 0.1 & 4027.65 & 895.577 & 1032.797 \\
FZI $\mu \mathrm{m}$ & 0.1 & 11.7 & 5.372 & 3.313 \\
\hline
\end{tabular}

of volume of connected pores per rock matrix volume to calculate current zone indicator (CZI, Eq. 10). The calculated values of the electric current zone indicator (CZI) for the studied samples are ranged from 0.26 to 0.57 with an average of 0.35 . Thereupon, three majors electric flow units (EFUs) were defined using four current zone indicator (CZI) classes including $0.3>\mathrm{CZI}>0.25,0.30>\mathrm{CZI}>0.35$, $0.35>\mathrm{CZI}<0.40$. There is only one sample of $\mathrm{CZI}<0.4$ out of detected units (Fig. 13). It shows that cementation exponents $(\mathrm{m}=--1.37,-1.36$ and -1.24$)$ are characterizing EFU 1, 2 and 3, respectively. These electric flow units which have been obtained are controlled by power equations (Table 6). This technique divides the Nubia sandstone samples into 3 populations with the same electrical parameters ( $\mathrm{a}$ and $\mathrm{m}$ ) as shown in Figs. 13 and 14. The tortuosity of studied samples was correlated with the three EFUs showing reliable coefficients of correlation as: $0.78,0.61$ and 0.75 , respectively. An attempt was made to correlate the estimated hydraulic flow units with electric flow units (Fig. 15) to either confirm each other's or not. They are displayed with one scale for both. It shows that the comparison between them illustrates very good matching in some parts for studied Nubia lithotypes, while in other parts they are slightly deviated. This may indicate that the two implemented techniques are slightly different in their resultant output. It may be due to their physical concepts. The studied samples have a fewer number of electric flow units than that obtained from hydraulic flow units. Figure 16 shows a crossplot between hydraulic and electric units is characterized by slightly scattered data points at low values of both flow units, but closely correlated at high values of both RQI $>1.0$ $\mu$ and ERI $>20 \%$ ).

\section{Conclusions}

- Petrographic investigation of the studied thin sections illustrates that the studied samples are mainly quartz arenite depending on rock framework and digenetic processes, and these processes were responsible for showing the relationship between porosity and permeability as a cluster with a low correlation coefficient.

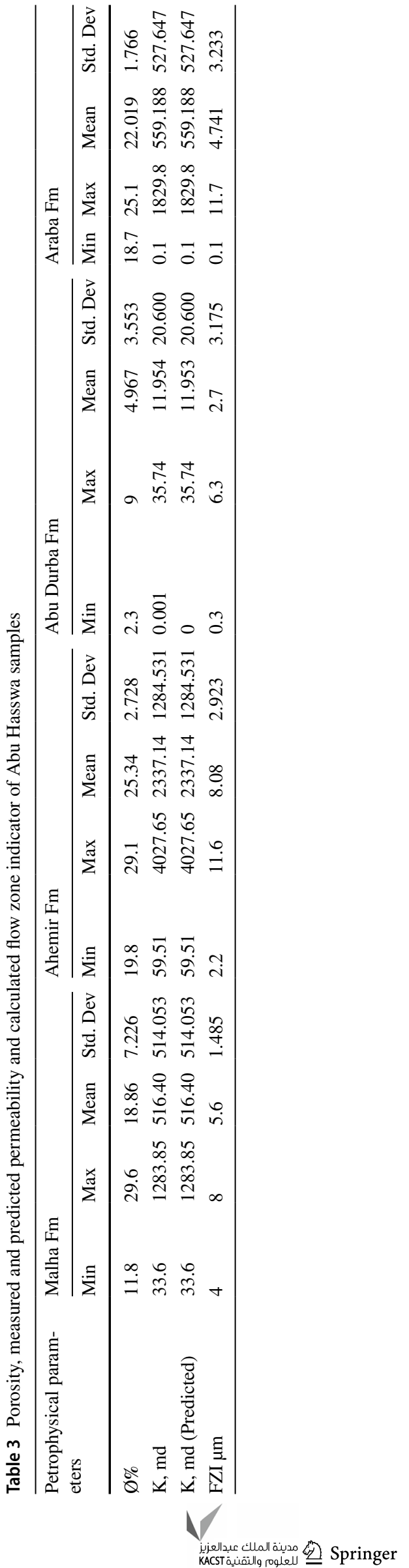




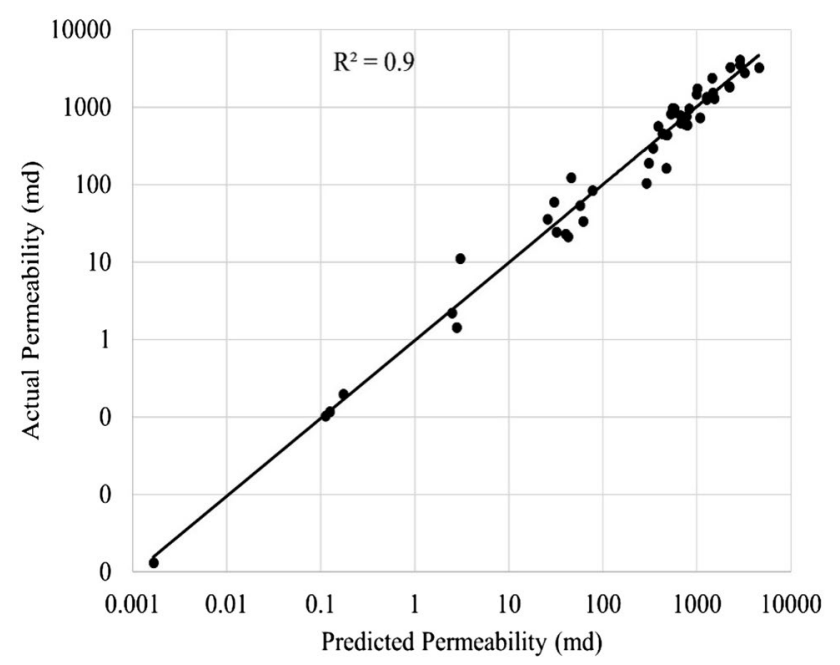

Fig. 11 The relation between actual and predicted permeability

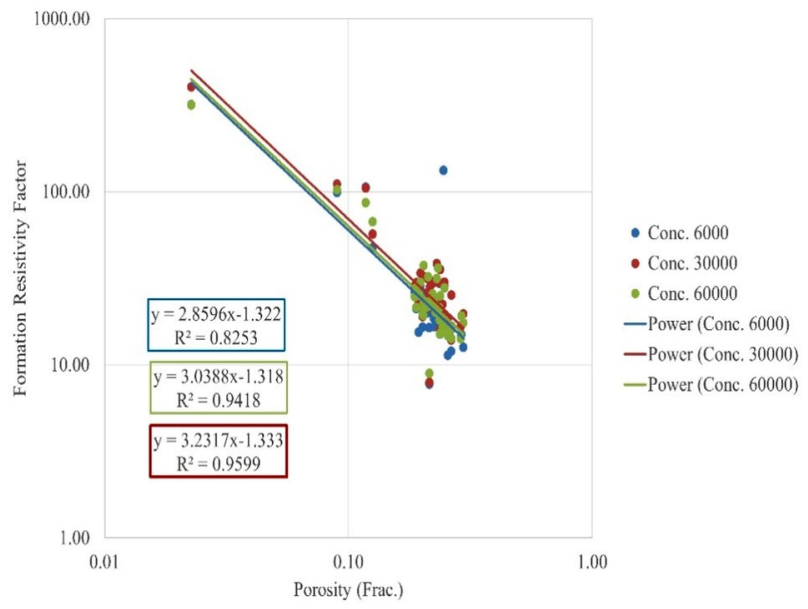

Fig. 12 The relation between formation resistivity factor calculated at three different successive brine concentrations and porosity of $\mathrm{Abu}$ Hasswa samples

Table 4 Electrical properties for the studied samples of Abu Hasswa section

\begin{tabular}{lllll}
\hline Electrical properties & Min & \multicolumn{1}{l}{ Max } & Mean & Std. Dev \\
\hline F @6000 ppm FF & 7.73 & 318.08 & 32.801 & 49.334 \\
F @30,000 ppm FF & 7.92 & 403.18 & 36.336 & 58.417 \\
F @60,000 ppm FF & 8.92 & 317.65 & 32.357 & 46.346 \\
Tortuosity @60,000 ppm & 1.38 & 3.19 & 2.264 & 0.338 \\
ERI@60,000 PPM & 0.01 & 0.16 & 0.099 & 0.029 \\
CZI@60,000 PPM & 0.26 & 0.57 & 0.352 & 0.048 \\
\hline
\end{tabular}

where F@6000 ppm is formation resistivity factor at 6000 ppm brine concentration; F @30,000 ppm is formation resistivity factor at 30,000 ppm brine concentration; F @60,000 ppm is formation resistivity factor at $60,000 \mathrm{ppm}$ brine concentration; ERI is electric radius indicator; and CZI is current zone indicator

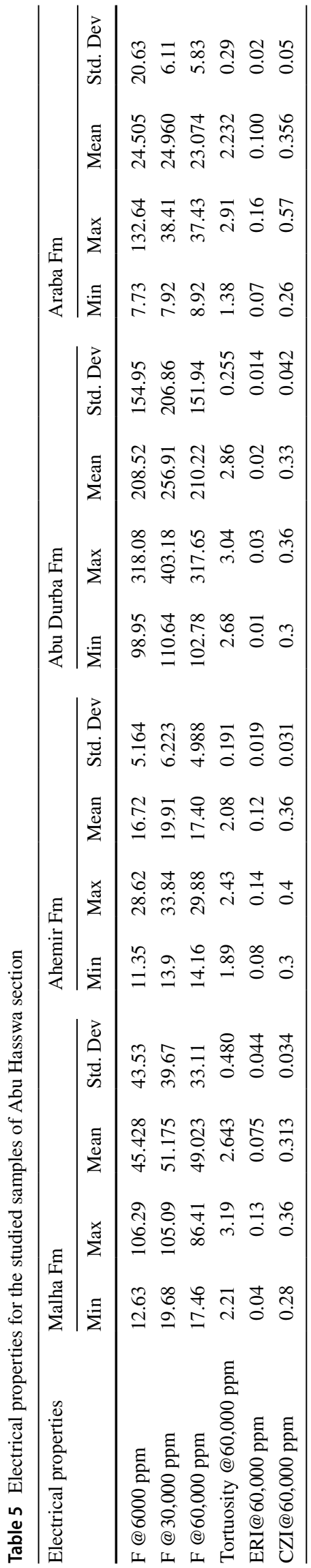




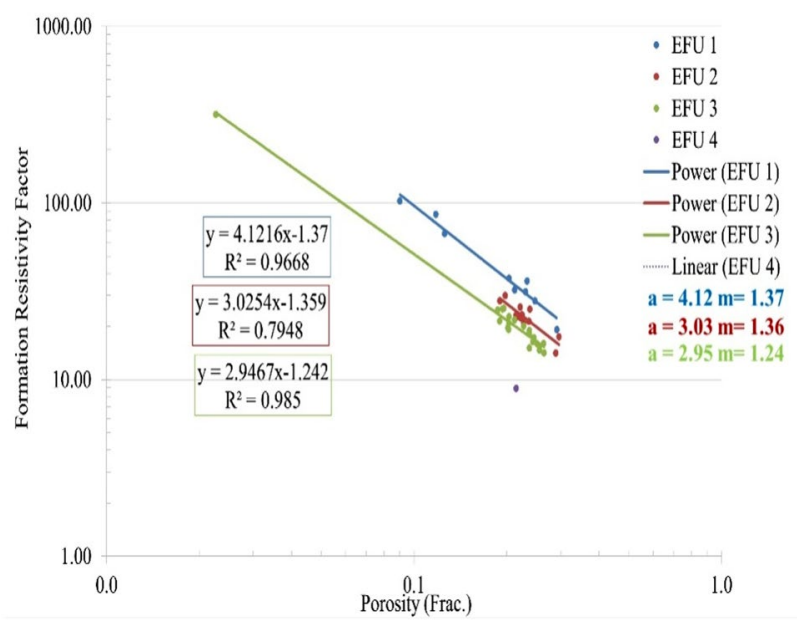

Fig. 13 The relation between the formation resistivity factor and porosity with CZI

Table 6 EFU equations, current zone indicator, $\mathrm{R}^{2}$ and cementation exponent $(\mathrm{m})$

\begin{tabular}{lllll}
\hline EFU & Equation & CZI & $\mathrm{R}^{2}$ & $\mathrm{M}$ \\
\hline EFU 1 & $\mathrm{F}=4.1216^{*} \emptyset^{-1.37}$ & 0.29 & 0.97 & -1.37 \\
EFU 2 & $\mathrm{F}=3.0254 * \varnothing^{-1.359}$ & 0.34 & 0.8 & -1.36 \\
EFU 3 & $\mathrm{F}=2.9467 * \varnothing^{-1.242}$ & 0.38 & 0.98 & -1.42 \\
\hline
\end{tabular}

where EFU is electric flow unit; $m$ is cementation exponent

- The main porosity-reducing factors are the cementation and/or the compaction, whereas rearrangement of cements through the time of digenesis inside pore spaces is the main porosity and permeability controlling factors, while the dissolution process caused oversized porosity and led to increase in porosity.

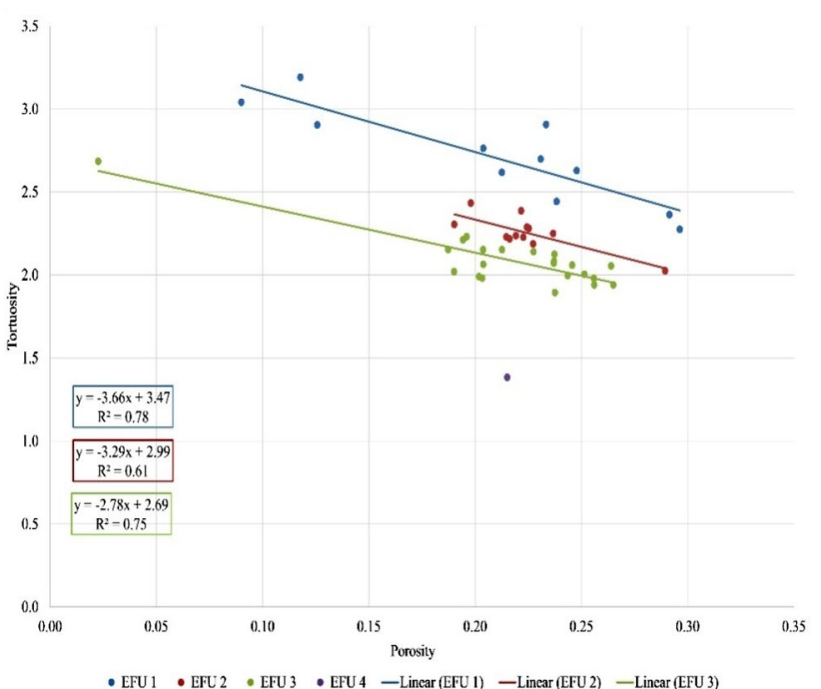

Fig. 14 The relation between tortuosity and porosity with EFUs

- The Nubia samples are classified into 5 HFUs different in their hydraulic qualities depending on their Winl and $\mathrm{R}_{35}$ values and FZI, where unit number-1 has the best reservoir quality and unit number-5 has the lowest reservoir quality. The predicted HFUs have 5 regression lines with power equations which have reliable correlation coefficients.

- The studied samples were classified into three major EFUs. This study suggests that the digenesis is responsible for the low number of EFUs, where the iron oxides as cementing materials acted as pore bridge increase electrical path ways conductivity.

- The comparison between ERI and RQI displayed a good correlation in samples with the same pore framework, while that exhibited a bad correlation for samples with complex diagenesis.

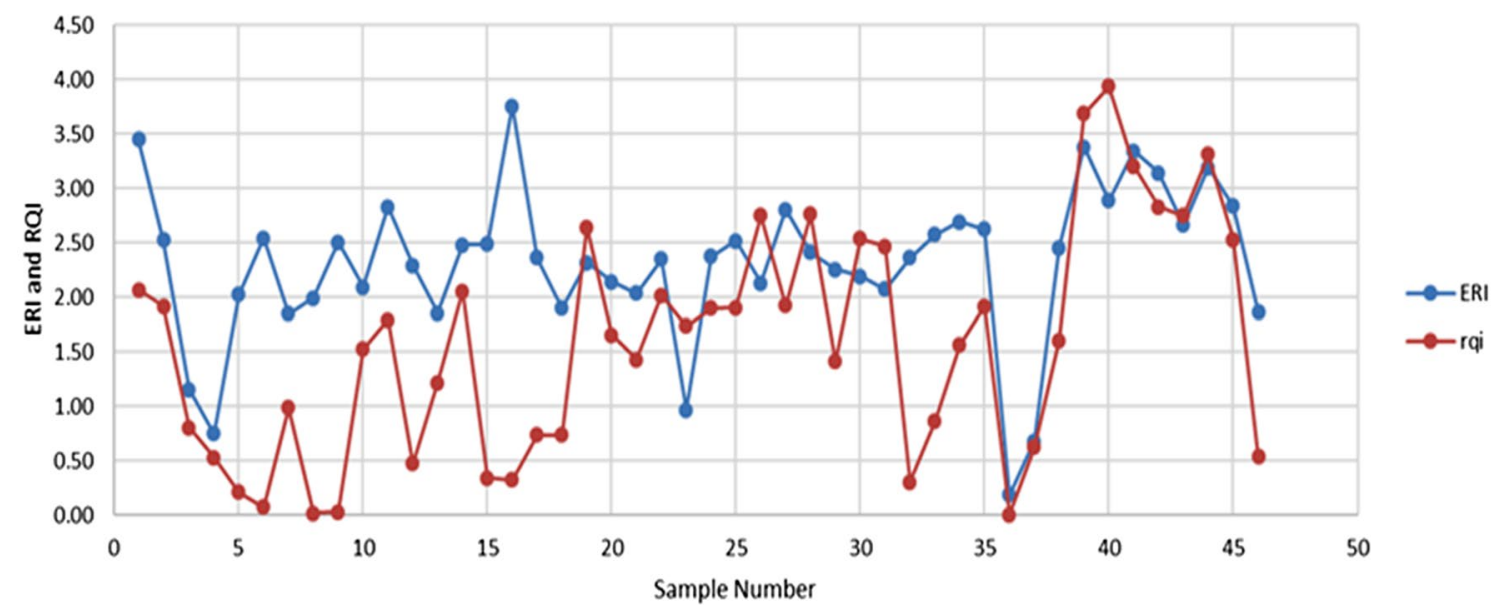

Fig. 15 The comparison between RQI (red) and ERI (blue) 


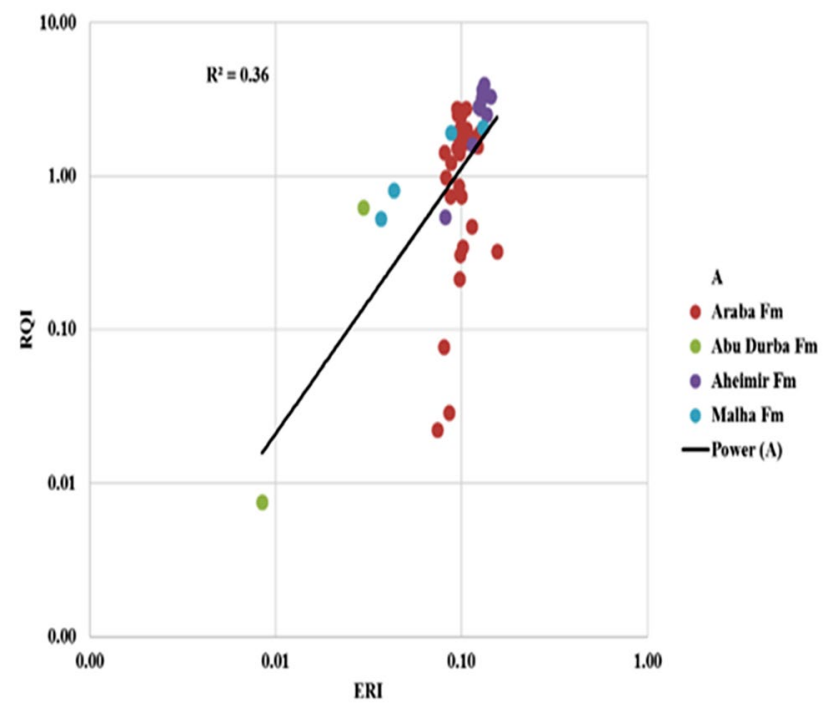

Fig. 16 The relation between ERI and RQI

Supplementary Information The online version contains supplementary material available at https://doi.org/10.1007/s13202-021-01242-x.

Funding We do not have a publication fund and support from our institutions. Your support is highly appreciated and sorry for not having a publication fund and support from our institutions.

Ethical statements This manuscript has not been submitted to more than one journal for simultaneous consideration. The submitted work is original and not has been published elsewhere in any form or language (partially or in full). Results are presented clearly, honestly and without fabrication, falsification or inappropriate data manipulation (including image-based manipulation).

Open Access This article is licensed under a Creative Commons Attribution 4.0 International License, which permits use, sharing, adaptation, distribution and reproduction in any medium or format, as long as you give appropriate credit to the original author(s) and the source, provide a link to the Creative Commons licence, and indicate if changes were made. The images or other third party material in this article are included in the article's Creative Commons licence, unless indicated otherwise in a credit line to the material. If material is not included in the article's Creative Commons licence and your intended use is not permitted by statutory regulation or exceeds the permitted use, you will need to obtain permission directly from the copyright holder. To view a copy of this licence, visit http://creativecommons.org/licenses/by/4.0/.

\section{References}

Abdallah AM, Adindani A (1965) Stratigraphy of upper Paleozoic rocks western side of Gulf of Suez. Geol Surv Min Res Dept, paper 25, Cairo

Abdel Moneim AA, Seleem EM, Zeid SA, Abdel Samie SG, Zaki S, Abu El-Fotoh A (2015) Hydrogeochemical characteristics and age dating of groundwater in the Quaternary and Nubian aquifer systems in Wadi Qena, Eastern Desert. Egypt Sustain Water Resour Manag 1:213-232

Al-Ajmi FA, Holditch SA (2000) Permeability estimation using hydraulic flow units in a Central Arabia reservoir. Proc SPE Ann Tech Conf Exhib OMEGA. https://doi.org/10.2523/63254-ms
Amaefule JO, Altunbay M, Tiab D, Kersey DG, Keelan DK (1993) Enhanced reservoir description: using core and log data to identify hydraulic (flow) units and predict permeability in uncored intervals/ wells. Proceedings-SPE Annual Technical Conference and Exhibition, Omega(c), 205-220. https://doi.org/10.2523/ 26436-ms

Al-Gamal AS (2011) An assessment of recharge possibility to NorthWestern Sahara Aquifer System(NWSAS) using environmental isotopes. J Hydrol 398:184-190

Alsharhan AS, Salah MG (1997) Litho-stratigraphy, Sedimentology and Hydrocarbon Habitat of the Pre-Cenomanian Nubian Sandstone in the Gulf of Suez Oil Province, Egypt. Geo-Arabia, Vol. 2, No. 4

Amaefule JO, Altunbay M, Tiab D, Kersey DG, Keelan DK (1993) Enhanced reservoir description: Using core and log data to identify hydraulic flow units and predict permeability in uncored intervals/wells. Society of Petroleum Engineers, paper 26436, 88th Annual Technical Conference and Exhibition, 205-220

API Specifications (1960) API recommended practices for core analysis procedure. RP 40, First Edition, August, p 49

David C, Bertauld D, Dautriat J, Sarout J, Menéndez B, Nabawy B (2015) Detection of moving capillary front in porous rocks using X-ray and ultrasonic methods. Front Phys 3(July):1-14. https:// doi.org/10.3389/fphy.2015.00053

El-Barkooky AN (1986) Stratigraphic framework of the Paleozoic in the Gulf of Suez region, Egypt. In: 1st international conference of the geology of the Arab World. Cairo University, Egypt (Abstract)

El Sayed AA, El Sayed NA (2019) Thermal conductivity calculation from P-wave velocity and porosity assessment for sandstone reservoir rocks. Geothermic 82:91-96

El Sayed AA, Zeidan MS (1983) Contribution to the formation resistivity factor- porosity relation" 2nd Ann. Meet. E.G.S. Proc 2:86-107

El-Gendy N, Barakat M, Abdallah H (2017) Reservoir assessment of the Nubian sandstone reservoir in South Central Gulf of Suez Egypt. J Afr Earth Sci 129:596-609. https://doi.org/10.1016/j. jafrearsci.2017.02.010

El-Rawy M, Smedt F De (2020) Estimation and mapping of the transmissivity of the nubian sandstone aquifer in the Kharga oasis, Egypt. Water (Switzerland), 12(2). https://doi.org/10.3390/w1202 0604.

El Sayed AMA (1995) Petrophysical characteristics of the Mamura Formation (Lower Cretaceous) Western desert , Egypt. Acta. Geologica, Hangarica, Vol. 38/3, pp.269-282

El Sayed AMA, Temraz M, Kassab M (2008) Nubia sandstone facies and its reservoir quality at wadiSaal, East central Sinai. Egypt Egypt J Petrol 17(2):103-118

El Sharawy MS, Nabawy BS (2016a) Determination of electrofacies using wireline logs based on multivariate statistical analysis for the Kareem Formation, Gulf of Suez, Egypt. Environ Earth Sci 75(21):1-15. https://doi.org/10.1007/s12665-016-6214-0

El Sharawy MS, Nabawy BS (2016b) Geological and Petrophysical Characterization of the Lower Senonian Matulla Formation in Southern and Central Gulf of Suez, Egypt. Arab J Sci Eng 41(1):281-300. https://doi.org/10.1007/s13369-015-1806-7

El Sharawy MS, Nabawy BS (2019) Integration of Electrofacies and Hydraulic Flow Units to Delineate Reservoir Quality in Uncored Reservoirs: A Case Study, Nubia Sandstone Reservoir, Gulf of Suez, Egypt. Nat Resour Res 28(4):1587-1608. https://doi.org/ 10.1007/s11053-018-9447-7

El Sharawy MS, Gamal RG (2019) Impacts of petrophysical properties of sandstone reservoirs on their irreducible water saturation: implication and prediction. J Afr Earth Sci 156:118-132

Garfunkel Z, Bartov Y (1977) The tectonics of Suez Rift. Geol. Surv. Israel Bull., 71 
Hassan AA (1967) A new Carboniferous occurrence in Abu-Durba, Sinai, Egypt: Proceedings of Sixth Arab Petroleum Congress, Baghdad, 2, 39 (B3)

Hassan A, Ahmed F, Atiq M, Arif F, Rehman AU, Abbasi I, Bregar U (2014) Integrated approach for facies identification and saturation height modelling; (case study from a middle indus stratigraphic field). Soc Petrol Eng PAPG/SPE Pakistan Sect Ann Tech Confer. https://doi.org/10.2118/174712-ms

Hassan NM, El Sayed AMA, Mousa SA, El-Bassiouni A (1994) Petrophysical and genetic body types of Pre-Cenomanian sandstones in Wadi Saal, east central Sinai, Egypt, Egy J Geol pp. 421-434

Hilfer R, Manwart C (2001) Permeability and conductivity for reconstruction models of porous media. Phys Rev E Stat Nonlinear Soft Matter Phys 64:021304. https://doi.org/10.1103/PhysRevE. 64.021304

Himida IH (1970) The Nubian Artesian Basin, its regional hydrogeological aspects and palaeo-hydrogeological reconstruction. J Hydrol 9:89-116

Issar A, Bein A, Michaeli A (1972) On the ancient water of the Upper Nubian Sandstone aquifer in central Sinai and southern Israel. J Hydrol North-Holland Publ Company 17(4):353-374

Kassab MA, Abu Hashish MF, Nabawy BS, Elnaggar OM (2017) Effect of kaolinite as a key factor controlling the petrophysical properties of the Nubia sandstone in central Eastern Desert, Egypt. J Afr Earth Sci 125:103-117. https://doi.org/10.1016/j. jafrearsci.2016.11.003

Kassab MA, Teama MA (2018) Hydraulic flow unit and facies analysis integrated study for reservoir characterisation: a case study of Middle Jurassic rocks at Khashm El-Galala, Gulf of Suez, Egypt. Arab J Geosci 11:294. https://doi.org/10.1007/s12517-018-3595-2

Khalil HM (1987) Geology of the area between Wadi Feiran and ElTor, south west Sinai, Egypt, M.Sc. Thesis, Tanta University, 130p

Kolodzie S, Jr (1980) Analysis of pore throat size \& use of the Waxmunmits equation to determine OOP in spindle field, Clorado society of petroleum Engineers, 55th Annual Fall Technical conference Paper 9382, 10p

Nabawy BS, Barakat MK (2017) Formation evaluation using conventional and special core analyses: Belayim Formation as a case study, Gulf of Suez, Egypt. Arab J Geosci 10(2):25

Nabawy BS, Géraud Y (2016) Impacts of pore- and petro-fabrics, mineral composition and diagenetic history on the bulk thermal conductivity of sandstones. J Afr Earth Sc 115:48-62. https://doi. org/10.1016/j.jafrearsci.2015.11.025

Rezaee MR, Motiei H, Kazemzadeh E (2007) A New Method to Acquire $m$ Exponent and Tortuosity Factor for Microscopically Heterogeneous Carbonates, an Example from Oligo-Miocene Asmari Formation, Southwest, Iran, Journal of Petroleum Science and Engineering, Vol. 56, issue 4
Robson DA (1971) The structure of the Gulf of Suez (Clysmic) rift, with special reference to the eastern side. J Geol Soc 127:247-276

Said R (1962) The geology of Egypt. Elsevier, New York, p 377

Sarhan MA, Basal AM (2019) Evaluation of Nubia sandstone reservoir as inferred from well logging data interpretation for Rabeh East-25 well, Southwest Gulf of Suez, Egypt. J Afr Earth Sci 155:124-136

Schutz KI (1994) Structure and Stratigraphy of the Gulf of Suez. Egypt APPG Mem 59:57-96

Slater L, Lesmes DP (2002) Electrical-hydraulic relationships for unconsolidated sediments. Water Resour Res 38(10):1213

Shabaninejad M, Bagheripour Haghighi M (2011) Rock typing and generalization of permeability- porosity relationship for an Iranian carbonate gas reservoir. Soc Petrol Eng Nigeria Ann Int Conf Exhib 2011:807-814. https://doi.org/10.2118/150819-ms

Shata AA (1982) Hydrogeology of the Great Nubian Sandstone basin, Egypt. Q J Eng GeolHydrogeol 15:127-133. https://doi.org/10. 1144/GSL.QJEG.1982.015.02.04

Shenawi SH, White JP, Elrafie EA, Kilany KA (2007) Permeability and water saturation distribution by lithologic facies and hydraulic units: A Reservoir Simulation Case Study: Society of Petroleum Engineers, SPE-105273-MS

Teama MA, Abuhagaza AA, Kassab MA (2019) Integrated petrographical and petrophysical studies for reservoir characterization of the Middle Jurassic rocks at Ras El-Abd, Gulf of Suez, Egypt. J Afr Earth Sci 152:36-47

Tiab D, Donaldson EC (2016) Petrophysics, theory, and practice of measuring reservoir rock and fluid transport properties. 4 th ed., Elsevier, p. 98

Wanas HA (2011) The lower paleozoic rock units in egypt: an overview, Geoscience Frontiers 2(4), 491e507, Elsevier, B.V

Williams JG, and Patel, Y. (2016) Fundamentals of cutting. Interface Focus, Royal Society 27274798, and ISSN: 2042-8901, volume 6 , issue 3.

Winland HD (1972) Oil accumulation in response to pore size changes. Amoco Production Company Report F72-G-25, Saskatchewan

Zhang X, Knackstedt MA (1995) Direct simulation of electrical and hydraulic tortuosity in porous solids. Geophys Res Lett 22(17):2333-2336

Publisher's Note Springer Nature remains neutral with regard to jurisdictional claims in published maps and institutional affiliations. 